\title{
Regional Overview on Maternal Nutrition and Examples of Health System Programme and Policy Responses: Asia and the Pacific
}

\author{
Angela de Silva $^{\text {a }}$ Juliawati Untoro $^{\mathrm{b}}$ Jessica Blankenship ${ }^{\mathrm{c}}$ \\ Emorn Udomkesmalee ${ }^{d}$
}

\begin{abstract}
${ }^{a}$ Nutrition and Health for Development Unit, Department of Noncommunicable Diseases, WHO Regional Office for South-East Asia, New Delhi, India; ${ }^{b}$ Nutrition Unit, Division of Noncommunicable Diseases and Health through the Life-Course, WHO Regional office for Western Pacific, Manila, Philippines; ${ }^{C}$ Nutrition Section, UNICEF Regional Office, East Asia and the Pacific, Bangkok, Thailand; ${ }^{d}$ Institute of Nutrition, Mahidol University, Nakhon Pathom, Thailand
\end{abstract}

\section{Keywords}

Maternal malnutrition · Foetal outcomes · Nutrition interventions · Coverage

\begin{abstract}
Background: The double burden of malnutrition in Asia and the Pacific is driving a renewed focus on maternal malnutrition. Summary: Though adverse consequences of maternal malnutrition have been long recognized, there is slow progress in addressing nutritional problems of women/adolescent girls. Coverage and quality of current maternal nutrition interventions, mostly delivered through antenatal care programmes vary across countries, and are often sub-optimum. Further, despite a marked increase in overweight and obesity in women of reproductive age, at present, most programmes are focused on under-nutrition and micronutrient deficiencies. Key Messages: The recent antenatal care recommendations released by World Health Organization provide a benchmark for countries to evaluate their programmes and identify gaps and challenges to improving maternal nutrition. Asian and Pacific countries need to address all forms of maternal malnutrition. For countries that historically focused on maternal under-nutrition, expanding their pro-
\end{abstract}

\begin{tabular}{ll}
\hline KARGER & $\begin{array}{l}\text { () World Health Organization } 2019 \\
\text { Published by S. Karger AG, Basel }\end{array}$ \\
E-Mail karger@karger.com & $\begin{array}{l}\text { All rights reserved. } \\
\text { This article is licensed under the Creative Commons Attribution- } \\
\text { www.karger.com/anm }\end{array}$ \\
& $\begin{array}{l}\text { NonCommercial-NoDerivatives 4.0 International License (CC BY- } \\
\text { NC-ND) (http://www.karger.com/Services/OpenAccessLicense) } \\
\text { Usage and distribution for commercial purposes as well as any dis- } \\
\text { tribution of modified material requires written permission. }\end{array}$
\end{tabular}

grammes to incorporate interventions to address overweight and obesity will be challenging. Innovative methods for nutrition counselling, both in terms of content and using novel channels of communication, are needed. Protocols and guidance on managing excessive weight gain as well as determining appropriate pregnancy weight gains are needed, while managing micronutrient deficiencies, particularly in settings where inherited disorders of red blood cells exist.

(c) World Health Organization 2019 Published by S. Karger AG, Basel

\section{Introduction}

Addressing maternal malnutrition and its drivers through health system interventions is of paramount importance in Asia. This paper presents a summary of discussions at the international symposium on the double burden of malnutrition (DBM) in December 2018 in a

The article is part of the Proceedings of the International Symposium on Understanding the Double Burden of Malnutrition for Effective Interventions organized by the International Atomic Energy Agency (IAEA) in cooperation with United Nations Children's Fund (UNICEF) and World Health Organization (WHO) (10-13 December 2018, Vienna, Austria).
Nutrition and Health for Development Unit, Department of Noncommunicable Diseases WHO Regional Office for South-East Asia, Red Fort Capital Parsvnath Tower 1 Bhai Vir Singh Marg, Gole Market, Sector 4, New Delhi 110001 (India) E-Mail desilvap@who.int 
session that focused on Asia. Multiple forms of malnutrition, including under-nutrition, micronutrient deficiencies and emerging overweight and obesity that coexist across most countries pose a significant challenge to fragile health systems and programmes. We share some data from countries facing these issues, identify information and data gaps that hamper effective delivery of primary health care programmes, and prioritize measures that are vital to improve maternal malnutrition in Asia.

\section{Epidemiology and Landscape}

Maternal malnutrition in low- and middle-income countries encompasses both under-nutrition and a growing problem with overweight and obesity [1]. Maternal under-nutrition and micronutrient deficiencies have declined in the past two decades, but continues to affect one-third of women of reproductive age in both World Health Organization's (WHO) South-East Asian and Western Pacific regions $[2,3]$. Concurrently, in many Pacific countries, the estimated prevalence of overweight is well over $50 \%$ in women of reproductive age [4]. South Asia also has the highest prevalence (28\%) of low birth weight globally [5], while both regions show ever increasing trends of adult obesity (BMI $\geq 30 \mathrm{~kg} / \mathrm{m}^{2}$ ) [6]. Stagnating levels of undernutrition, including micronutrient deficiencies, have serious implications for maternal, new-born, and child health, as well as intergenerational impacts. If adolescents or women are undernourished during pregnancy, the cycle of maternal malnutrition, foetal growth restriction, child stunting, a subsequent lifetime of impaired productivity and increased maternal and foetal morbidity and mortality are perpetuated [2]. Children who are born low birth weight have a greater risk of stunting and wasting with increased susceptibility to the metabolic syndrome. Maternal obesity is associated with increased rates of miscarriage, gestational diabetes, caesarean section due to obstructed labour and adverse new-born outcomes [7]. Recent evidence also points to intergenerational effects of overweight and obesity [7]. Therefore, a greater emphasis on nutrition for adolescent girls and young women before, during and after pregnancy is warranted.

\section{Programmatic Experiences}

Although the adverse consequences of maternal malnutrition have been long recognized and evidence-based interventions have been articulated, progress in addressing nutritional problems of women and adolescent girls has been slow. Interventions include providing iron, folate, and calcium supplements to pregnant women, nutrition education and counselling on healthy diets during antenatal care, and energy and protein supplements to undernourished women [8].

Most maternal nutrition policies and their implementation in South Asia and Western Pacific Regions are geared towards reducing under-nutrition and micronutrient deficiencies. The WHO Global Nutrition Policy Review (GNPR 2016-2017) provides an overview of country priorities for maternal nutrition and related outcomes [9]. The GNPR reports that in the WHO South-East Asia Region, 9 out of 11 countries had goals, targets or indicators related to low birth weight in their national policies, while in the Western Pacific Region, 15 of 26 countries had low birth weight as a national target. Reported actions for maternal nutrition also focus mainly on under-nutrition, with $90-100 \%$ of countries reporting programmes for delivery of iron supplementation to women of reproductive age and/or pregnant women in both regions, and $90 \%$ reporting fortification of food-grade salt with iodine [9]. While nutrition counselling is an integral part of antenatal care, the quality of counselling, especially in cases of overweight and obesity, is unclear [10].

Good nutrition in adolescent girls contributes significantly to the health of future pregnancies. Focusing on the nutrition of adolescent girls is important, as is preventing adolescent pregnancies. The GNPR reported that, both in Asia and Pacific countries, strategies aimed at adolescent girls were few, with only 57 and $42 \%$ of countries in the WHO South-East Asia Region and the Western Pacific Region, respectively, having set programme objectives related to preventing under-nutrition in adolescents [9]. Data from the region highlights the need for attention to adolescent nutrition. An analysis of Demographic Health Survey data from 2000 to 2017 found a high prevalence of chronic energy deficiency and anaemia among adolescent girls. Moreover, it was reported that pregnant adolescents are chronically energy deficient and almost $20 \%$ of adolescent girls are anaemic [11]. Unfortunately, these data are rather consistent across many countries in Asia, but provide a clear impetus to advocate for expanding the nutrition policy focus towards adolescents, to integrate surveillance data on adolescent health, and to carry out specific interventions to improve adolescent nutrition.

The main service delivery platform for maternal nutrition is through antenatal care services within primary health care systems. Coverage and quality of current maternal nutrition interventions vary across countries and within regions and are often sub-optimum [12-14]. For example, coverage of iron supplementation in women is inadequate in many countries and scaling up of interven- 
tions poses challenges in terms of human resources, access and demand for services [12-14]. While the need for implementing interventions for overweight and obese women is increasing across countries, concrete actions are few. The maternal health programmes in the Philippines mirrors the reality of many countries that report a DBM. Maternal nutrition interventions focus on delivery through antenatal care platforms of iron, folic acid and zinc supplementation, nutrition counselling, and food supplementation in specific areas and have been successful in reducing the prevalence of low birth weight $[5,13]$. However, despite the increasing prevalence of obesity among women, standards for nutritional assessment of pregnant women and guidance on pregnancy weight gain are not available, nor are protocols for the management of obesity among pregnant women.

In addition to programmatic considerations, inadequate usage of available data is a barrier to policy and programme interventions. Attempts are underway to increase use of data to inform policy. An example of an innovative project in 3 ASEAN countries (Indonesia, Philippines and Thailand) is the analysis of maternal nutrition status and dietary data. Inputs are initially received from policy and programme managers regarding specific data needs and available national data is used to construct policy-relevant data analysis, focusing on the first 1,000 days. The presidential decree to scale up nutrition in Indonesia provides a policy framework to demonstrate the evidence-informed process. In the Philippines, data from periodic National Nutrition Surveys is used to focus on chronic energy deficits and food-insecure pregnant and lactating women. In Thailand, the focus is in the Ministry of Health's recently launched project "Miracle of 1,000 days". This project will provide inputs for strengthening data and informing policy and similar analysis could ideally be mainstreamed in other countries too.

The Global Strategy for Women's, Children's and Adolescents' Health, 2016-2030, has provided a recent advocacy impetus towards scaling up maternal health and nutrition policy measures [15]. The accompanying "Every Woman Every Child" platform puts women, children and adolescents at the heart of the new Sustainable Development Goals. The recent WHO recommendations on antenatal care for a positive pregnancy experience have created further policy space around maternal nutrition interventions and provide a benchmark for countries to assess gaps and to identify specific needs, especially in the context of the DBM [8]. To prioritize areas in need of practical implementation guidance, capacity development and implementation research, particularly relevant for South-East

Preventing Maternal Malnutrition in Asia and the Pacific
Asia and Western Pacific, UNICEF recently initiated landscape analyses in 6 ASEAN countries and in 8 South Asian countries [16]. These review the country status against the WHO recommendations and prioritize actions to improve maternal nutrition. Continued advocacy and provision of support by international partners and global platforms to sustain the focus on maternal health is essential.

\section{Recommendations and Conclusions}

Double duty actions for maternal nutrition and points of action at the programme level with a focus on programme quality is essential. To do so, the information that maternal nutrition is a key determinant of health and disease of future generations must be understood and emphasized at all levels of government and other stakeholders. Policymakers should also be mindful that pregnant women may not simply be underweight or overweight, but have metabolic conditions that affect foetal metabolic status. One could pose the policy question "How is the drive to reduce low birth weight succeeding in improving the anthropometric profile of children?" Innovations in nutrition counselling, apart from delivery through the health centre, should explore large-scale communication, social behaviour change communication messaging, social media, and other networks. Protocols and guidance on managing excessive weight gain as well as determining appropriate pregnancy weight gain in Asian and Pacific countries are urgently needed. Managing micronutrient deficiencies, especially anaemia prevention in settings where inherited disorders of red blood cells exist, also needs attention.

\section{Conclusion}

In summary, the discussions highlighted the complexity of maternal nutrition in Asia and Pacific Regions. Actions that are vital to improving maternal nutrition were prioritized and many examples discussed the need for formative and implementation research. A collective and collaborative effort will be needed to identify and fill the gaps in evidence along with a specific research agenda to best inform capacity development and implementation. Together, these and other initiatives, including healthful food environments that are being promoted across the Asia and $\mathrm{Pa}$ cific region, are likely to contribute to improving the nutritional status of adolescents and pregnant women. Nonetheless, broader and more coordinated efforts andinitiatives are needed to address the DBM in the Asia and Pacific Regions. 


\section{Acknowledgement}

We thank the following panellists who participated in the Regional Symposium on Addressing the DBM; Double duty actions in the health system response to reduce maternal malnutrition: Petra Salame, IAEA, Drs. Jovie Raval and Anthony Calibo from the Ministry of Health, Republic of the Philippines and Prof. Chittaranjan Yajnik, KEM Hospital and Research Centre, Pune, India and the rapporteur of the session, Katie Bates.

\section{Statement of Ethics}

The authors have no ethical conflicts to disclose for this review because there were no humans or animals involved directly.

\section{Disclosure Statement}

The authors have no conflicts of interest to declare. The views and opinions expressed in this article are those of the authors and do not necessarily reflect the official policy or position of WHO or UNICEF. The presentation of material therein does not imply the expression of any opinion whatsoever on the part of WHO or UNICEF.

\section{Funding Sources}

No external funding source contributed to the writing of this paper. Open access provided with a grant from the International Atomic Energy Agency.

\section{Author Contributions}

The authors contributions were as follows: All authors conceptualized the paper. A.S. wrote the paper with contributions from all authors, who reviewed and provided technical comments. All authors read and approved the final manuscript. A.S., J.U., J.B., and E.U. agree to be accountable for all aspects of the work in ensuring that questions related to the accuracy or integrity of any part of the work are appropriately investigated and resolved.

\section{Disclaimer}

The statements, opinions and data contained in this publication are solely those of the individual authors and contributors, not of the publishers and the editor(s), and do not necessarily reflect the views of the cooperating organizations, IAEA, UNICEF and WHO. The use of particular designations of countries or territories does not imply any judgement by the cooperating organizations, as to the legal status of such countries or territories, of their authorities and institutions or of the delimitation of their boundaries. The mention of names of specific companies or products (whether or not indicated as registered) does not imply any intention to infringe proprietary rights, nor should it be construed as an endorsement or recommendation on the part of the cooperating organizations.

\section{References}

1 ASEAN/UNICEF/WHO. Regional Report on Nutrition Security in ASEAN. Volume 2. Bangkok: UNICEF; 2016.

2 Black RE, Victora CG, Walker SP, Bhutta ZA, Christian P, de Onis M, et al.; Maternal and Child Nutrition Study Group. Maternal and child undernutrition and overweight in lowincome and middle-income countries. Lancet. 2013 Aug;382(9890):427-51.

3 Regional Office for South-East Asia, World Health Organization. 2016. SEA/RC69/ 16Rev.3: Strategic action plan to reduce the double burden of malnutrition in the SouthEast Asia Region 2016-2025. WHO Regional Office for South-East Asia. http://www.who. int/iris/handle/10665/246276.

4 Chen C, Xu X, Yan Y. Estimated global overweight and obesity burden in pregnant women based on panel data model. PLoS One. 2018 Aug;13(8):e0202183.

5 World Health Organization. 2014. Global nutrition targets 2025: low birth weight policy brief. World Health Organization. http:// www.who.int/iris/handle/10665/149020.

6 Food and Agriculture Organization. 2018. Asia and the Pacific Regional Overview of Food Security and Nutrition 2018 - Accelerating progress towards the SDGs.
7 Kassebaum NJ, Barber RM, Bhutta ZA, Dandona L, Gething PW, Hay SI, et al.; GBD 2015 Maternal Mortality Collaborators. Global, regional, and national levels of maternal mortality, 1990-2015: a systematic analysis for the Global Burden of Disease Study 2015. Lancet. 2016 Oct;388(10053): 1775-812.

8 World Health Organization. WHO recommendations on antenatal care for a positive pregnancy experience: executive summary. World Health Organization. 2016. http:// www.who.int/iris/handle/10665/250800.

9 World Health Organization. Global nutrition policy review 2016-2017: country progress in creating enabling policy environments for promoting healthy diets and nutrition. Geneva: World Health Organization. 2018. https://www.who.int/nutrition/publications/policies/global_nut_policyreview_2016-2017/en/

10 Nguyen PH, Frongillo EA, Sanghvi T, Kim SS, Alayon S, Tran LM, et al. Importance of coverage and quality for impact of nutrition interventions delivered through an existing health programme in Bangladesh. Matern Child Nutr. 2018 Oct; 14(4): e12613.
11 Benedict RK, Schmale A, Namaste S. 2018. Adolescent Nutrition 2000-2017: DHS Data on Adolescents Age 15-19. DHS Comparative Report No. 47. Rockville: ICF.

12 Ministry of Health and Sports (MoHS) and ICF. Myanmar Demographic and Health Survey 2015-16. Nay Pyi Taw, Myanmar, and Rockville. Maryland, USA: Ministry of Health and Sports and ICF; 2017.

13 Ministry of Health. Nepal; New ERA; and ICF. 2017. Nepal Demographic and Health Survey 2016: Key Indicators. Kathmandu, Nepal: Ministry of Health, Nepal.

14 National Institute of Population Research and Training (NIPORT), Mitra and Associates, and ICF International. Bangladesh Demographic and Health Survey 2014. Dhaka, Bangladesh, and Rockville. Maryland, USA: NIPORT, Mitra and Associates, and ICF International; 2016.

15 The Global Strategy for Women's, Children's and Adolescents' Health (2016-2030). Every Woman Every Child 2015.

16 Goudet S, Murira Z, Torlesse H, Hatchard J, Busch-Hallen J. Effectiveness of programme approaches to improve the coverage of maternal nutrition interventions in South Asia. Matern Child Nutr. 2018 Nov; 14 Suppl 4:e12699. 